\title{
The effect of short-term meteorological disturbances on the submerged aquatic vegetation and associated fauna in the Patos Lagoon estuary, southern Brazil: a dataset.
}

Dairana Misturini ${ }^{* 1,2}$, Marianna Lanari ${ }^{3}$, Valéria Lemos ${ }^{4}$, Leonir André Colling ${ }^{5}$

\section{ABSTRACT}

Occluded fronts are naturally cyclogenic areas that have been intensified by global warming. Studies evaluating the effects of occluded fronts in the submerged aquatic vegetation (SAV) and its associated fauna in shallow estuarine areas may provide insights on the impacts of climate change-induced extreme weather events on coastal ecosystems functioning. The present dataset describes data on benthic fauna and flora in the Patos Lagoon Estuary (PLE), in southern Brazil, seasonally obtained during intense occluded fronts. Using a hierarchical sample design, based on Beyond BACl protocols (Before/After and Control/Impact), fauna and flora were sampled before and after four occluded fronts passage throughout 2019. Three habitats were sampled: SAV Meadow, SAV Edge and adjacent Sandflat. A total of 432 macrozoobenthic samples (216 samples for stratum); 216 samples for bellow and aboveground biomass, vegetation coverage, canopy height and marine macrophytes morphology; 144 samples by sedimentology and organic matter; 72 water column depth measurements; and 8 temperature and salinity measurements were collected during the study period. The data is available at the Global Biodiversity Information Facility (GBIF), in Darwin Core standard format (DwC), organized according to the OBIS-ENV-DATA model, with CC-BY-NC-4-0 license for use. The present dataset adds to the comprehension of the temporal variability of estuarine benthic communities in subtropical systems, and how short-term meteorological process can affect zoo and fitobenthic communities in the context of climate changes.

Keywords: Benthic Fauna; Seagrass; Sandflat; Occluded Front; Sedimentary Organic Matter.

\footnotetext{
1 Programa de Pós-graduação em Oceanografia Biológica - Universidade Federal do Rio Grande, Rio Grande, RS, Brasil. dairana.dai@gmail.com.

2 Universidade Federal de Santa Catarina, Coordenadoria Especial de Oceanografia, Laboratório de Biodiversidade Costeira, Florianópolis, SC, Brasil.

${ }_{3}^{3}$ Universidade Federal do Rio Grande, Laboratório de Ecologia Vegetal Costeira, Rio Grande, Brasil.

${ }^{4}$ Universidade Federal do Rio Grande, Laboratório de Ictiologia, Rio Grande, Brasil.

${ }^{5}$ Universidade Federal de Rio Grande, Laboratório de Ecologia de Macroinvertebrados Bentônicos, Rio Grande, Brasil.
} 


\section{PRIOR PUBLICATIONS}

MISTURINI, D. A Influência de Sistemas Frontais sobre as Assembleias Bentônicas de Pradarias de Fanerógamas Submersas Estuarinas (Master Dissertation, Universidade Federal do Rio Grande). 2021.

MISTURINI, DAIRANA; COLLING, L. A. Can short-term meteorological events alter subtropical estuarine macrobenthic assemblages in seagrass meadows (Patos Lagoon Estuary-Southern Brazil)?. Estuarine, Coastal and Shelf Science, p. 107532, 2021. DOI: https://doi.org/10.1016/j.ecss.2021.107532

\section{DATA IMPORTANCE}

- The dataset provides information about temporal variation in subtropical estuarine habitats;

- Integration of these data with other similar datasets can add to the comprehension of the effects of SAV on benthic macrofaunal diversity and abundance in subtropical estuarine areas;

- The data have information about different quali and quantitative variations generated by four occluded fronts, in different scenarios of intensity and habitat complexity, for macrozoobenthic organisms and canopy characteristics;

- The dataset offer insights on the influence of patchiness, composition, morphology of seagrass species and edge effect in the structure of macrozoobenthic assemblage.

\section{MATERIALS AND METHODS}

\section{Study area}

The Patos Lagoon is the largest coastal lagoon in South America with $\sim 11,000 \mathrm{~km}^{2}$. The estuarine area ( 170 $\mathrm{km}^{2}$; hereafter PLE) comprising shallow flats (> $1.5 \mathrm{~m}$ depth) and a deeper main channel (CALLIARI; CUNHA; ANTIQUEIRA, 2010). Located between the latitudes $31^{\circ}$ and $32^{\circ} \mathrm{S}$, the Patos Lagoon estuary (PLE) (Fig. 1) is situated in a humid subtropical region, with the frequency of occluded fronts passages being variable between seasons (STECH; LORENZZETTI, 1992). The hydrodynamics and physicochemical characteristics of PLE are highly dependent of local and remote winds action, fluvial discharge (mainly by rivers Guaíba, Camaquã and São Gonçalo channel) and regional precipitation (MOLLER et al., 2001). The estuarine region is dominated by riverine discharges and becomes oligohaline in raining season (winter and spring). During Summer and Autumn, local hydrology is mainly controlled by NE and SW wind and eurihaline scenarios prevail (MOLLER et al., 2001).

\section{Field sampling}

This study is a short-term research demanded by the Brazilian Long-Term Ecological Research Program (BR-LTER) in the Patos Lagoon Estuary and adjacent marine coast (PLEA). The study was performed in the northern margin of the Justino Bay (Fig. 1, detail), a shallow estuarine area with local hydrodynamics and physical-chemical parameters strongly affects by southwestern winds. The sampled area was surrounded by salt marshes, sandflats and, similarly to other estuarine shoals (SEELIGER; ODEBRECHT, 2010), also presented seasonal variations in the SAV structure and abundance.

The field works were carried out hours or one day before and after four occluded fronts passage, using before as control, according to $\mathrm{BACl}$ model (Before/After, Control/Impact; UNDERWOOD, 1996). Sampling fieldwork were in Summer (B: 2019/03/08 and A: 2019/03/13), Autumn (B: 2019/05/08 and A: 2019/05/13), Winter (B: 2019/08/23 and A: 2019/08/28) and Spring (B: 2019/11/08 and A: 2019/11/18). Sampling followed a hierarchical model where submerged aquatic vegetation (SAV) Meadow, Sandflat and 
SAV Edge habitats were sorted. The sampled habitats were divided in transects $(T 1, T 2, T 3)$, creating a $400 \mathrm{~m}^{2}(20 \mathrm{~m} \times 20 \mathrm{~m})$ delimitated squares.

Figure 1. South America, Brazil and Rio Grande do Sul (top left), where the Patos Lagoon Estuary is located (PLE; top left) and the sampling area in the Justino Bay-SJ (shaded in black).

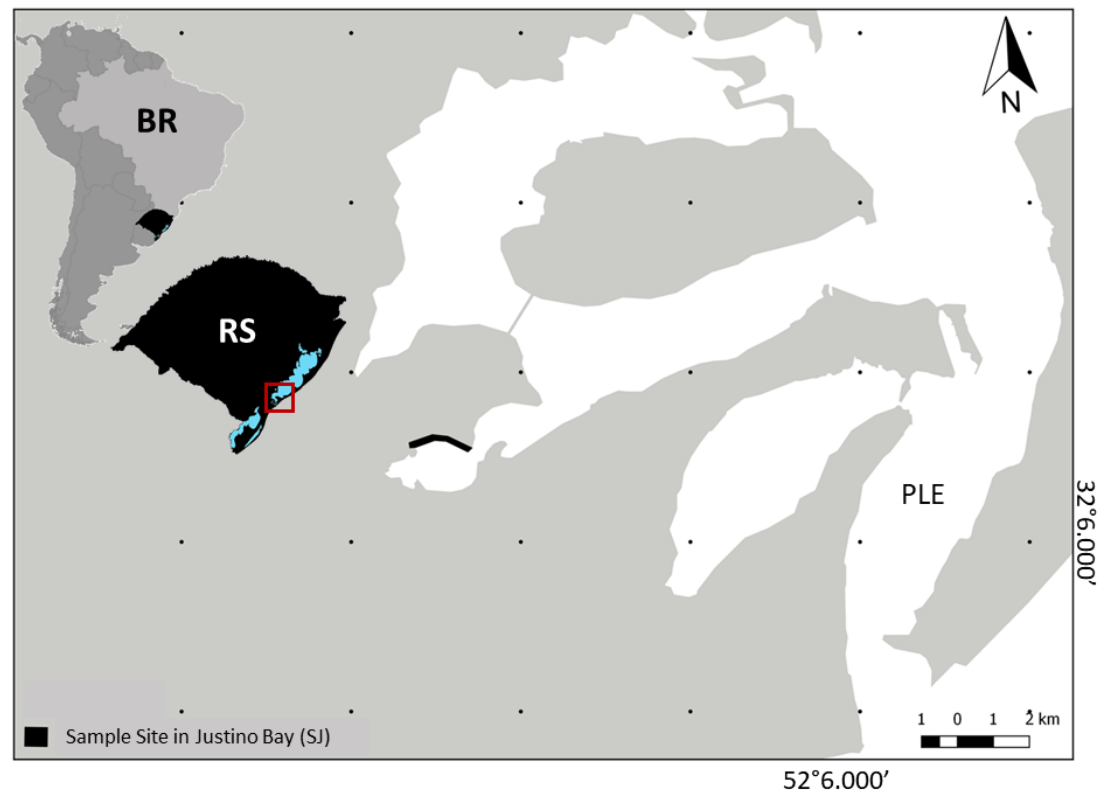

\section{Biological Parameters}

During each sampling event, SAV visual coverage and canopy height (quadrat, $1 \mathrm{~m}^{2}$ ), and biomass (core: $0.1 \mathrm{~m} \varnothing \times 0.1 \mathrm{~m}$ depth) were collected in each transect and habitat ( $\mathrm{N}$ total $=$ 216 samples). In the laboratory, plants fresh biomass was separated from macrobenthic organisms and sorted out in R. maritima/ $Z$. palustris and in P.striatus according to leaf morphology. Below (roots and rhizomes) and aboveground (shoots and leaves) biomass were separated for dry weight determination (48 h, 60 ${ }^{\circ} \mathrm{C}$; MCKENZIE et al., 2003).

Benthic macrofauna were sampled using a cylindrical core $\left(0.008 \mathrm{~m}^{2}\right)$. The sedimentary package was removed from the core, placed in a tray and stratified in the $0.1 \mathrm{~m}$ surface sample and $0.1 \mathrm{~m}$ to $0.2 \mathrm{~m}$ bottom sample, with a spatula, for each transect and habitat ( $\mathrm{N}$ total $=216$ samples for each stratum). The samples were sieved through a $300 \mu \mathrm{m}$ mesh and kept fresh just to presort fauna and flora. In the laboratory, the samples were identified and classified to the lowest possible taxonomic level based on morphological and anatomical characteristics, was fixed with $4 \%$ formalin, identified and preserved in alcohol $70 \%$.

\section{Environmental Parameters}

Surface water temperature (mercury thermometer) and salinity (portable RHO-90 refractometer) were taken at the beginning of each field sampling. Sediment samplings were performed in duplicate for each transects and habitat with a cylindrical core $\left(0.002 \mathrm{~m}^{2}, 0.1 \mathrm{~m}\right.$ depth, total $\mathrm{N}=144$ ) for granulometric analyses and determination of organic matter content. Granulometry was analyzed using the method described by Suguio (1973). Organic matter content was determined by the loss on ignition method (DAVIES, 1974).

\section{Quality control}

The sampled material was processed by specialists, based on accepted and applied 
manuals for sampling (LANA et al., 2006; TURRA; DENADAI, 2015), taxonomy (RIOS, 1994; ARENZON, 1999; AMARAL; RIZZO; ARRUDA, 2006; BUCKUP; BOND-BUCKUP; LARKUM; ORTH; DUARTE, 2006) and methodology (SUGUIO, 1973; DAVIES, 1974; LAVERY; KENDRICK, 2001). Taxonomic validity was verified using the World Register of Marine Species (WoRMS; www.marinespecies.org) and in National Center for Biotechnology Information (https://www.ncbi.nlm.nih.gov).

\section{DATA DESCRIPTION}

This dataset contains environmental data, morphology and characteristics of SAV data, and benthic macrofauna quali and quantitative data. A total of 432 macrozoobenthic samples (216 samples for stratum); 216 samples for biomass, vegetal coverage, canopy height and marine macrophytes morphology; 144 samples by sedimentology and organic matter; 72 water column depth measurements; and 8 temperature and salinity measurements were seasonally collected. After meteorological events the data differed from the initial (i.e., Before treatments), in this way, we suggest the use of data before events for studies aiming to compare estuarine benthic communities structure and composition.

VAS showed a seasonal trend with higher values in Summer (EV1) and lowers in Winter (EV3). The presence of $R$. maritima was registered throughout the year and $P$. striatus only in Summer (EV1) and Spring (EV4). All vegetation data were expressed per meter or square meter.

Figure 2. Frequency of macrozoobenthic organisms classes in this dataset. "Other" refers to classes whose total density was less than 625 indv. $\mathrm{m}^{-2}$.

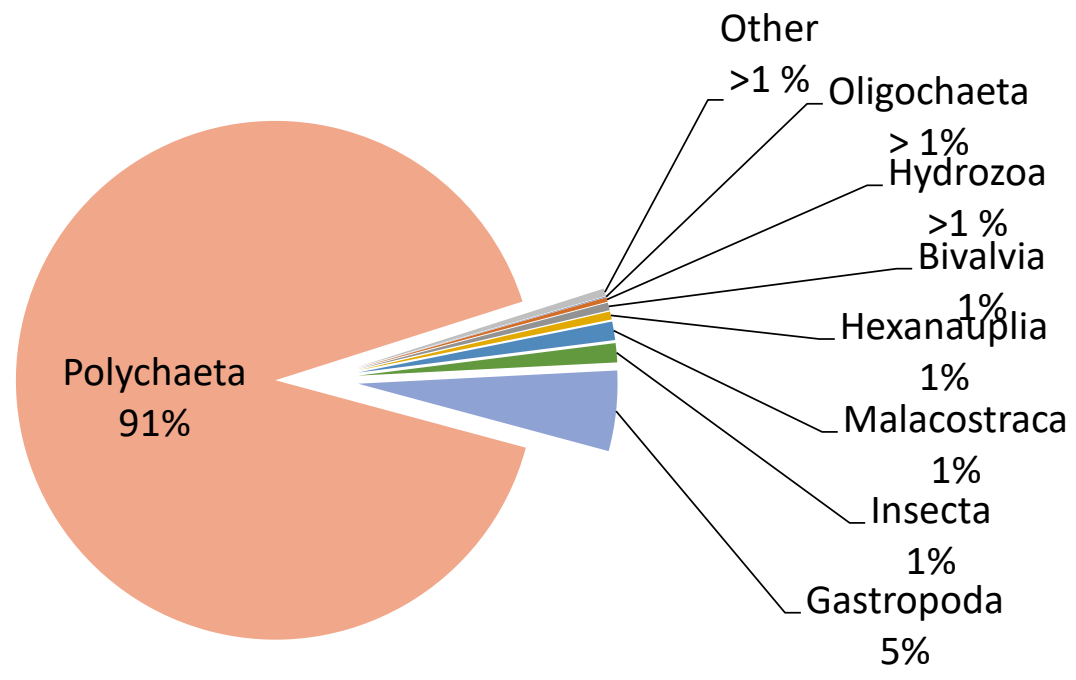

Our equipment aimed capture benthic macrofauna and marine macrophytes, but we registered other SAV associated fauna occurrence. The associated fauna was constituted by abundant meiofauna, megafauna, limnic organisms, terrestrial insects, planktonic organisms, the complete taxonomic coverage are

in Table 1. A total of 13.828 brackish water macrozoobenthic organisms, distributed across 20 taxa. A total 890 epifaunal organisms and 12.938 infaunal organisms were collected and the most frequent class were the Polychaeta (91\%) and Gastropoda (5\%; Fig 2). The number of organisms is expressed in density $\left(\mathrm{m}^{2}\right)$. 
Table 1. List of taxa found in the sampling area during 2019. Note that taxa were identified at distinct taxonomic levels. The first column represents the species identifiers numbers at the end of the occurrencelD code in dataset. Sp. ID: Specie Identification in occurrencelD; K: Kingdom; P: Phylum; C: Class; O: Order; F: Family; G: Genus; S: Specie.

\begin{tabular}{|c|c|c|c|c|c|c|c|}
\hline $\begin{array}{l}\text { Sp } \\
\text { ID }\end{array}$ & K & $\mathbf{P}$ & C & 0 & $\mathbf{F}$ & G & $\mathbf{S}$ \\
\hline 3 & \multirow{38}{*}{ 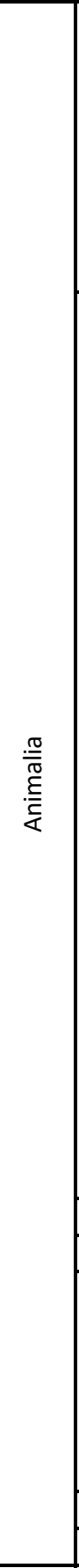 } & \multirow{7}{*}{$\begin{array}{l}\frac{\pi}{0} \\
\frac{0}{4} \\
\frac{5}{4} \\
\frac{5}{4}\end{array}$} & \multirow{6}{*}{$\begin{array}{l}\frac{\pi}{ \pm} \\
0 \\
\frac{0}{0} \\
\frac{0}{0} \\
0\end{array}$} & \multirow{3}{*}{ Phyllodocida } & Nephtyidae & Nephtys & Nephtys fluviatilis \\
\hline 4 & & & & & \multirow{2}{*}{ Nereididae } & Alitta & Alitta succinea \\
\hline 1 & & & & & & Laeonereis & Laeonereis acuta \\
\hline 16 & & & & Spionida & Spionidae & Paraprionospio & $\begin{array}{l}\text { Paraprionospio } \\
\text { pinnata }\end{array}$ \\
\hline 14 & & & & \multirow{2}{*}{ Capitellida } & \multirow{2}{*}{ Capitellidae } & Capitella & Capitella natoi \\
\hline 2 & & & & & & Heteromastus & Heteromastus similis \\
\hline 15 & & & \multicolumn{5}{|l|}{ Oligochaeta } \\
\hline 38 & & \multirow{22}{*}{$\begin{array}{l}\frac{\pi}{0} \\
\frac{0}{0} \\
\frac{0}{0} \\
\frac{1}{2} \\
\frac{T}{2}\end{array}$} & \multirow{6}{*}{$\begin{array}{l}\stackrel{0}{\mathscr{d}} \\
\stackrel{心}{\subseteq}\end{array}$} & \multicolumn{4}{|l|}{ Coleoptera } \\
\hline 11 & & & & \begin{tabular}{|l} 
Diptera \\
\end{tabular} & \multicolumn{3}{|l|}{ Chironomidae } \\
\hline 35 & & & & Hemiptera & \multicolumn{3}{|l|}{ Cicadellidae } \\
\hline 39 & & & & \multicolumn{4}{|l|}{ Hemiptera } \\
\hline 25 & & & & \multicolumn{4}{|l|}{ Hymenoptera } \\
\hline 36 & & & & \multicolumn{4}{|l|}{ Odonata } \\
\hline 41 & & & \multirow{10}{*}{ 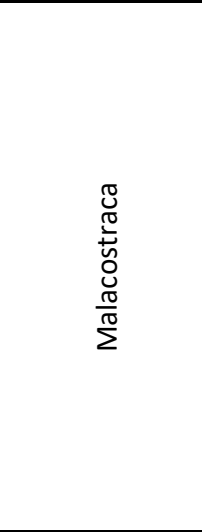 } & Cumacea & Diastylidae & Diastylis & Diastylis sympterygiae \\
\hline 42 & & & & \multirow{3}{*}{ Decapoda } & Portunidae & \multicolumn{2}{|l|}{ Callinectes } \\
\hline 9 & & & & & Varunidae & Cyrtograpsus & \begin{tabular}{|l|} 
Cyrtograpsus \\
angulatus
\end{tabular} \\
\hline 34 & & & & & \multicolumn{3}{|l|}{ Penaeidae } \\
\hline 26 & & & & \multirow[t]{2}{*}{ Isopoda } & Sphaeromatidae & Cassidinidea & \begin{tabular}{|l|} 
Cassidinidea \\
fluminensis \\
\end{tabular} \\
\hline 18 & & & & & Munnidae & Uromunna & Uromunna peterseni \\
\hline 7 & & & & \multicolumn{4}{|l|}{ Mysidacea } \\
\hline 8 & & & & \multicolumn{4}{|l|}{ Amphipoda } \\
\hline 28 & & & & \multirow[t]{2}{*}{ Tanaidacea } & Kalliapseudidae & $\begin{array}{l}\text { Monokalliapse } \\
\text { udes }\end{array}$ & $\begin{array}{l}\text { Monokalliapseudes } \\
\text { Schubarti }\end{array}$ \\
\hline 33 & & & & & Tanaididae & Sinelobus & Sinelobus Stanfordi \\
\hline 40 & & & Arachnida & Trombidiformes & & & \\
\hline 17 & & & Hexanaunlia & Sessilia & Balanidae & & \\
\hline 37 & & & 7еxailaupia & & & & \\
\hline 32 & & & Entognatha & & & & \\
\hline 20 & & & Branchiopoda & Diplostraca & & & \\
\hline 27 & & & Ostracoda & & & & \\
\hline 43 & & Chordata & Thaliacea & Salpida & Salpidae & & \\
\hline 19 & & Cnidaria & Hydrozoa & & & & \\
\hline 5 & & & $\frac{\pi}{8}$ & & & & Heleobia australis \\
\hline 13 & & & 응 & Littorinimorpha & Cochliopidae & Heleobia & Heleobia charruana \\
\hline \begin{tabular}{r|}
6 \\
23
\end{tabular} & & 肻 & 壳 & & & & \\
\hline 22 & & & & Myida & Corbulidae & Erodona & Erodona mactroides \\
\hline 21 & & & Bivalvia & Cardiida & Solecurtidae & Tagelus & Tagelus plebeius \\
\hline 31 & & Nematoda & & & & & \\
\hline 24 & & Nemertea & & & & & \\
\hline 29 & $\underset{\pi}{\pi}$ & & Tubothalamea & Miliolida & & & \\
\hline 30 & $\begin{array}{l}\frac{E}{0} \\
\text { ㄹํ }\end{array}$ & Foraminifera & & & & & \\
\hline 46 & & 岳 & 医 哭 党 & $\frac{\tilde{g}}{\tilde{m}}$ & Potamogetonaceae & Potamogeton & \begin{tabular}{|l|} 
Potamogeton striatus \\
\end{tabular} \\
\hline 44 & $\frac{\pi}{2} \pi$ & $\stackrel{2}{\circ} \frac{0}{8}$ & $\sum^{\infty} \frac{\overline{0}}{0} \cdot \underline{0}$ & $\frac{\pi}{\pi}$ & Ruppiacea & Ruppia & Ruppia maritima \\
\hline
\end{tabular}




\begin{tabular}{|c|c|c|c|c|c|c|c|}
\hline $\begin{array}{l}S p \\
\text { ID }\end{array}$ & $\mathbf{K}$ & $\mathbf{P}$ & C & 0 & $F$ & G & S \\
\hline 45 & & & & & Zannichelliaceae & Zannichellia & Zannichellia palustris \\
\hline
\end{tabular}

\section{Dataset}

The dataset was formatted according to the Darwin Core standard (DwC) and organized in the OBIS-ENV-DATA model (DE POOTER et al., 2017). The file contain an event and location spreadsheet (Event core; Table 2), a species occurrence list spreadsheet (Occurrence extension) and a quantitative environmental parameters, benthic density and SAV biomass, coverage, morphology and canopy height data spreadsheet (ExtMoF). Darwin Core terms used for each field column is listed in Table 2 . Environmental parameters were described with Natural Environment Research Council (NERC).

Table 2. Dwc terms and their meanings according to the Darwin Core vocabulary.

\begin{tabular}{|c|c|c|}
\hline Spreadsheet & Field & Definition \\
\hline \multirow{21}{*}{ Event core } & datasetName & Dataset unique identifier \\
\hline & institutionID & The name of institution having custody of the dataset. \\
\hline & institutionCode & The name of institution having custody of the dataset. \\
\hline & rightsHolder & An organization managing the data rights. \\
\hline & parentEventID & Identifier for Event that groups the Events. \\
\hline & eventID & A unique identifier constructed based on event information. \\
\hline & eventDate & The date of field work resented in the Year-Month format. \\
\hline & Locality & The locality in Patos Lagoon which sampling events occurred. \\
\hline & locationID & An identifier for locality and habitat which field work are made. \\
\hline & Country & The country in which sampling events occurred. \\
\hline & countryCode & The standard code for country. \\
\hline & stateProvince & The state in which sampling events occurred. \\
\hline & waterBody & The name of the water body where sampling occurred. \\
\hline & Habitat & The habitat which sampling events occurred. \\
\hline & samplingProtocol & Type of sampler method, which defines the sampling protocol. \\
\hline & samplingEffort & $\begin{array}{l}\text { The measure for effort that was expended during a sampling } \\
\text { event. }\end{array}$ \\
\hline & sampleSizeValue & The size of the sample. \\
\hline & sampleSizeUnit & $\begin{array}{l}\text { Sampler size transformation }\left(0.008 \mathrm{~m}^{2}\right) \text { to obtain organisms } \\
\text { density. }\end{array}$ \\
\hline & geodeticDatum & Spatial reference system upon which the geographic coordinates. \\
\hline & decimalLatitude & The geographic latitude of sampling area. \\
\hline & decimalLongitude & The geographic longitude of the sampling area. \\
\hline \multirow{8}{*}{$\begin{array}{l}\text { Occurence } \\
\text { extension }\end{array}$} & basisOfRecord & The origin of the data, such as museum or sample. \\
\hline & occurrencelD & $\begin{array}{l}\text { A unique identifier providing information of biological } \\
\text { occurrence. }\end{array}$ \\
\hline & taxonRank & The most specific name in the scientific name field. \\
\hline & occurrenceStatus & A statement about the presence or absence of a Taxon. \\
\hline & scientificName & The full scientific name, with authorship and date \\
\hline & scientificNamelD & Number identifier of organism \\
\hline & scientificNameAuthorship & The authorship information for the scientificName. \\
\hline & Kingdom & The kingdom in which the taxon is classified. \\
\hline
\end{tabular}




\begin{tabular}{|c|c|c|}
\hline Spreadsheet & Field & Definition \\
\hline & Phylum & The phylum or division in which the taxon is classified. \\
\hline & Class & The class in which the taxon is classified. \\
\hline & Order & The order in which the taxon is classified. \\
\hline & Family & The family in which the taxon is classified. \\
\hline & Genus & The genus in which the taxon is classified. \\
\hline & specificEpithet & The species in which the taxon is classified. \\
\hline & collectionCode & The laboratory where the collection was deposited \\
\hline & identifiedBy & Name of the author who identified the organisms. \\
\hline & recordedBy & The responsible for recording the original Occurrence. \\
\hline & bibliographicCitation & The bibliographic reference must be cited when the data is used. \\
\hline \multirow{9}{*}{ ExtMoF } & measurementID & Identifier related to the type of measurement performed. \\
\hline & measurementType & The measurement name type according to NERC. \\
\hline & measurementTypeID & The identifier for measurement type according to BODC. \\
\hline & measurementValue & The value of the measurement. \\
\hline & measurementvalueID & The measurement value ID. \\
\hline & measurementUnit & The units related to measurement value according to NERC. \\
\hline & measurementUnitID & A measurement unit according to the BODC \\
\hline & measurementMethod & The method used to determine the measurement. \\
\hline & Remarks & Reference or protocol used to obtain the measurements. \\
\hline
\end{tabular}

NERC: Natural Environment Research Council; BODC: British Oceanographic Data Center

The abbreviations created to identify place, occurrence and measurement in dataset, such as are in the diagram below (Fig. 3).

\section{SUPPLEMENTARY MATERIALS}

Repository: Global Biodiversity Information Facility (GBIF). | DOI: https://doi.org/10.15468/v2dd3g Links to access: https://www.gbif.org/dataset/04167aa4-4148-4691-a264-031922765fc1

\section{ACKNOWLEDGEMENTS}

The Brazilian Long-Term Ecological Research Program has been supported by MCTI (Ministério de Ciência, Tecnologia e Inovação) and the Brazilian governmental funding agencies CNPq (Conselho Nacional de Desenvolvimento Científico e Tecnológico, Process NUMBER: CNPq/CAPES/FAPs/BC - Fundo Newton/PELD no 15/2016), CAPES (Coordenação de Aperfeiçoamento Pessoal de Nível Superior), FAPERGS (Fundação de Amparo à Pesquisa do Rio Grande do Sul), and the Newton Funding (British Council), the Organization for the Conservation of South American Aquatic Mammals. Additional support came from CNPq, which provided research fellowships to author D.M. V.M.L was financially supported by CAPES with a postdoctoral scholarship. 
Figure 3. Schema with abbreviations to identify dataset IDs. Codes for strata $(10,20)$, replicates $(a, b, c)$, transects $(t 1$, t2, t3), habitats (sf, e, sm), periods before (B1, B2, B3, B4) and after (A1, A2, A3, A4) events (2019:3, 2019:5, 2019:8, 2019:11), sampled at Justino Bay (SJ), PLE (patos), BR, as part of the LTER-PLEA and deposited at Benthic Ecology Laboratory (benthos), Oceanographic Institute (IO), Federal University of Rio Grande (FURG). Highlight for the biotic, in green background (top), and abiotic data, in orange (bottom). The red asterisks mark each measurementID specification.

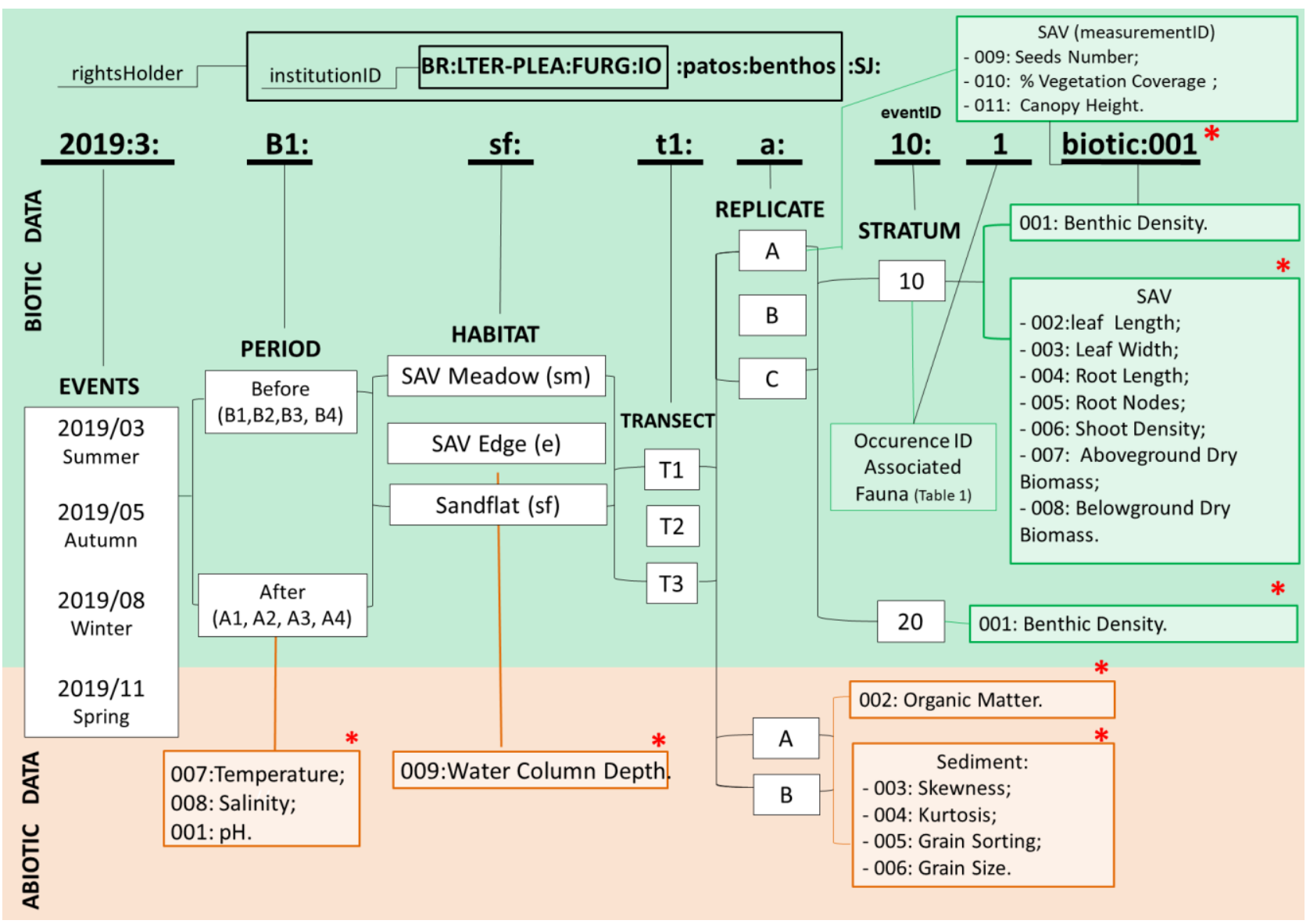

\section{REFERENCES}

AMARAL, A. C. Z.; RIZZO, A. E.; ARRUDA, E. P. Manual de identificação dos invertebrados marinhos da região sudeste-sul do Brasil. [s.I.] EdUSP, v. 1, 2006.

BUCKUP, L.; BOND-BUCKUP, G.; ARENZON, A. Os crustáceos do Rio Grande do Sul. Porto Alegre: Editora da Universidade, Universidade Federal do Rio Grande do Sul, 1999.

CALLIARI, L.; CUNHA, R. P. DA; ANTIQUEIRA, J. A. F. DE. Geomorfologia e Dinâmica Sedimentar. In: SEELIGER, U.; ODEBRECHT, C. (Eds.). . O estuário da Lagoa dos Patos: um século de transformações. 1. ed. Rio Grande: FURG, p. 31-43. 2010.

DAVIES, B. E. Loss-on-ignition as an estimate of soil organic matter. Soil Science Society of America Journal, v. 38, n. 1, p. 150-151, jan. 1974.

DE POOTER, D. et al. Toward a new data standard for combined marine biological and environmental datasets - Expanding OBIS beyond species occurrences. Biodiversity Data Journal, v. 5, n. 1, 2017.

LANA, P. DA C. et al. Avaliação ambiental de estuários brasileiros: diretrizes metodológicas. serie livr ed. Rio de JAneiro: Museu Nacional, 2006.

LARKUM, A. W. D.; ORTH, R. J.; DUARTE, C. Seagrasses: Biology, Ecologyand Conservation. 1. ed. Dordrecht: Springer Netherlands, 2006. 
LAVERY, P.; KENDRICK, G. Assessing biomass, assemblage structure and productivity of algal epiphytes on seagrasses. 2001.

MCKENZIE, L. J.; CAMPBELL, S. J.; RODER, C. A. Seagrass-Watch: manual for mapping \& monitoring seagrass resources by community (citizen) volunteers. 2. ed. Quensland: Seagrass-Watch: Manual for Mapping \& Monitoring Seagrass Resources by Community (citizen) volunteers, 2003.

MOLLER, O. O. et al. The influence of local and non-local forcing effects on the subtidal circulation of Patos Lagoon. Estuaries, v. 24, n. 2, p. 297, 2001. DOI: https://doi.org/10.2307/1352953.

RIOS, E. C. Seashells of Brazil. 2. ed. Rio Grande: Fundação Cidade do Rio Grande, Fundação Universidade do Rio Grande, Museu Oceanográfico, 1994.

SEELIGER, U.; ODEBRECHT, C. O Estuário da Lagoa dos Patos: um século de transformações. 1. ed. Rio Grande: Universidade Federal do Rio Grande - FURG, 2010.

STECH, J. L.; LORENZZETTI, J. A. The Response of the South of Wintertime Brazil Bight to the Passage Cold Fronts. Journal of Geophysical Research, v. 97, n. 6, p. 9507-9520, 1992. DOI: https://doi.org/10.1029/92JC00486.

SUGUIO, K. Introdução à sedimentologia. São Paulo: E. Blücher, 1973.

TURRA, A.; DENADAI, M. R. Protocolos para o monitoramento de habitats bentônicos costeiros - Rede de Monitoramento de Habitat Bentônicos Costeiros - ReBentos. [s.I.] Instituto Oceanográfico da Universidade de São Paulo, 2015.

UNDERWOOD, A. J. On Beyond Baci. In: SCHMITT, R. J.; OSENBERG, C. W. B. T.-D. E. I. (Eds.). Detecting Ecological Impacts. San Diego: Elsevier, 1996. p. 151-175. 